\title{
Mais Festschriften para Stella Esther Ortweiler Tagnin
}

\author{
Luciana Carvalho Fonseca \\ Rozane Rebechi \\ Patrícia Tosqui-Lucks
}

0 grande número de submissões decorrentes da chamada para este número especial da TradTerm, desmembrado em dois volumes, reflete o prestígio e reconhecimento do trabalho da Professora Stella Tagnin como uma das precursoras da Linguística de Corpus no Brasil, bem como sua ampla rede de pesquisa no país e fora dele.

Este volume é composto por doze artigos e uma entrevista. 0 interesse de pesquisa da homenageada pela área da culinária já dura mais de uma década, frutificando trabalhos como REBECHI; TAGNIN, 2020; TAGNIN, 2015a, 2015b; TAGNIN; ALVINO; CORRÊA, 2017; TEIXEIRA; TAGNIN, 2008, além de diversas orientações. Assim, os primeiros artigos deste número corroboram o gosto pelo tema. Para além dos aspectos culinários, o volume como um todo possui marcante aspecto cultural por incluir incursões na interface da Linguística de Corpus com o ensino da tradução, idiomaticidade, terminologia, fraseologia e literatura, e nas culturas brasileira, portuguesa, chinesa, italiana, inglesa, irlandesa e estadunidense.

0 primeiro artigo é Learning from others' experience: A taste of parallel corpus analysis for translation students and budding corpus researchers, de Silvia Bernardini, professora da Universidade de Bologna. No artigo, a autora descreve o potencial da análise de um corpus paralelo para o desenvolvimento de habilidades

TradTerm, São Paulo, v.37, n. 2, janeiro/2021, p. 364-369

Número Especial - Linguística de Corpus www.revistas.usp.br/tradterm 
tradutórias, usando um texto culinário da virada do século 19: La scienza in cucina e l'arte del mangiar bene de Pellegrino Artusi em sua versão original italiana e na tradução para o inglês.

O segundo artigo, intitulado Expressões idiomáticas com a temática alimentação: tradução e glossário de 'Pepinos e Abobrinhas' de Márcio Alemão, de autoria de Janaína M. da Silva e Elisa Duarte Teixeira, ambas da UnB, coloca em xeque a (in)traduzibilidade da linguagem figurada entre diferentes línguas e culturas apoiada no prescritivismo. A partir de diferentes traduções realizadas por estudantes, as autoras organizaram um glossário, que pode ser uma importante ferramenta para que os tradutores mantenham, na tradução, a idiomaticidade observada no texto de partida que se utiliza de expressões idiomáticas da área da alimentação.

Em Sobre a busca por equivalentes funcionais em um corpus comparável português-inglês de críticas gastronômicas, Rozane Rebechi, Giulia Rotava e Patrícia Freitag, as três filiadas à UFRGS, descrevem o percurso da construção do Dicionário Gastronômico de termos e fraseologias em português e inglês, a partir de um corpus comparável de críticas gastronômicas. As autoras focam as diferenças culturais que devem ser consideradas na tradução de textos da área, e que vão muito além da equivalência terminológica nos dois idiomas.

No artigo As lost as a pun in a corpus: an investigation into noncanonical phraseological occurrences in large corpora and translation, Adauri Brezolin, professor titular da Universidade Metodista de São Paulo, discute a ideia de fixidez, analisando variações e jogos de palavras de unidades fraseológicas. 0 autor analisa formas não-canônicas em corpora e a tradução de jogos de palavras ligados à política atual brasileira encontrados na mídia, com resultados criativos e surpreendentes.

Em seguida, o artigo Semantics of 'hard' and 'soft' in relation to Brexit, de Vlatko Broz, professor visitante na Universidade Federal do ABC, analisa a semântica da 'dureza' e 'leveza' em relação ao substantivo 'Brexit' em um corpus de notícias. Os resultados demonstram como a prosódia semântica de uma descrição metafórica 
é negociada, em parte, por meio de sinônimos que exageram ou mitigam suas associações positivas ou negativas.

Professor da Beijing Normal University e da Hong Kong Baptist University, John Corbett nos brinda com uma detalhada análise da forma como a cultura anglófona imagina e nomeia os irlandeses, baseando-se no Historical Thesaurus of English, no projeto Mapping Metaphor e no Hansard Corpus of British Parliamentary Speeches. No artigo, intitulado Terminology and the evolution of linguistic prejudice: The conceptual domain of 'Irishness' in the Historical Thesaurus of English and the Hansard Corpus of British Parliamentary Speeches, o autor explica como o conceito de Irishness resulta em metáforas relacionadas à raiva.

No artigo Características do texto traduzido na obra de Conan Doyle: um estudo baseado em Linguística de Corpus, Natalyany Nunes Oliveira e Nilson Roberto Barros da Silva, ambos da Universidade do Estado do Rio Grande do Norte, apoiamse em Baker (1996) para afirmar que há características comuns aos textos traduzidos, independentemente das línguas fonte e alvo; entre elas, a explicitação e a simplificação. 0 objetivo do trabalho foi investigar, com base em Linguística de Corpus, a presença dessas características na tradução da obra de Conan Doyle para o português.

Da literatura de Conan Doyle, para a literatura infantil, Jamilly Brandão, pósgraduanda da Universidade de São Paulo, relata, no artigo Entre coisas selvagens, monstros e feras: as traduções de 'Where The Wild Things Are' para o português brasileiro e para o chinês, a construção e análise inicial de um corpus paralelo composto por esse livro infantil original em inglês e suas traduções, a fim de analisar e comparar as traduções publicadas nas duas línguas. A autora emprega não só as ferramentas de Linguística de Corpus, mas também questionário a falantes nativos de chinês.

Em Linguística de Corpus, Fraseologia e seriados televisivos: análise contrastiva de unidades fraseológicas em Game of Thrones, Joel Victor Reis Lisboa, pós-graduando da Universidade Federal de Uberlândia, apresenta uma análise contrastiva de cinco unidades fraseológicas extraídas de um corpus bilíngue de 
legendas do seriado televisivo Game of Thrones, à luz da taxonomia proposta por Tagnin (2013). 0 artigo evidencia as possibilidades da exploração lexical do mundo ficcional dos seriados televisivos para os estudos fraseológicos, bem como a aplicabilidade da referida taxonomia para a classificação e análise das unidades fraseológicas.

Em Explorando o vestuário na literatura em português, Diana Santos, professora na Universidade de Oslo e membro da Linguateca, apresenta os passos percorridos no sentido de elucidar os motivos pelos quais foram identificadas muito mais menções a peças de vestuário em textos literários brasileiros do que em suas contrapartes portuguesas. Um dos resultados do projeto Guarda-Fatos, essa contribuição versa sobre as vantagens de se partir de dados quantitativos antes de o analista se debruçar nos textos que compõem o corpus em análise.

Assim como o artigo anterior, os últimos dois artigos deste número trazem aspectos da cultura brasileira. Em Investigating the influence of culture on language patterns: a contrastive corpus-based study, Sandra Navarro, doutora pela Universidade de São Paulo, aborda a intrínseca relação entre linguagem e cultura e busca lançar luz sobre as associações culturais implícitas no significado colocacional. A pesquisa combina os princípios da Linguística de Corpus e dos Estudos Interculturais ao investigar um corpus de resenhas de viajantes (inglês/português) e a autora interpreta os resultados com base em um modelo de orientações culturais.

Encerrando a seção de artigos, Trio elétrico ou bandwagon? Um estudo das estratégias de tradução de referentes culturais em textos turísticos, de Giovana Marqueze, da Universidade de São Paulo, aborda os referentes culturais em textos turísticos. A autora analisa e discute as estratégias empregadas nas traduções do português para o inglês de textos publicados pela EMBRATUR.

0 número especial se encerra com uma detalhada entrevista, intitulada Linguística de Corpus no Brasil, ontem e hoje: entrevista atualizada com Stella Tagnin, realizada por Elisa Duarte Teixeira (TEIXEIRA, 2017) e revista especialmente para este número. 0 texto foi publicado originalmente no periódico Belas Infiéis, a quem aproveitamos para agradecer a cessão de uso.

TradTerm, São Paulo, v.37, n. 2, janeiro/2021, p. 364-369

Número Especial - Linguística de Corpus www.revistas.usp.br/tradterm 
Por fim, as co-editoras gostariam de agradecer, mais uma vez, por todas as submissões, não só as que compõem o número. Agradecemos aos autores e autoras pelas trocas, aos pareceristas cegos e cegas pelo trabalho fundamental e voluntário e ao CITRAT - Centro Interdepartamental de Tradução e Terminologia - que edita a TradTerm sob o olhar atento de sua Comissão Editorial, a quem agradecemos a oportunidade.

Para as editoras, foi uma honra trabalhar na edição deste número em celebração da Professora Stella Tagnin e de seus 46 anos de USP, de seus 20 anos dedicados à Linguística de Corpus, de seu conhecimento compartilhado, de sua rede de solidariedade e de sua generosidade abundante. Obrigada por encarnar um exemplo de vida acadêmica saudável e reconhecida e por ser uma inspiração para todas nós.

Salve, Stella!

\section{Referências}

REBECHI, R.; TAGNIN, S. E. O. Brazilian cultural markers in translation: A model for a corpus-based glossary. Research in Corpus Linguistics, v. 8, p. 65-85, 2020.

TAGNIN, S. E. O. Corpus-Driven Glossaries in Translator Training Courses. Simões, Barreiro, Santos, Sousa-Silva \& Tagnin (eds.). Linguística,Informática e Tradução: Mundos que se Cruzam, v. 7, n. 1, p. 359-370, $2015 a$.

TAGNIN, S. E. O.; ALVINO, J. B.; CORRÊA, C. B. Questões de alinhamento e anotação semântica em um corpus de traduções inglês<>português: o CorTrad. Tradução em Revista, v. 22, n. 1, p. 39-63, 2017.

TAGNIN, T., Stella E. O. A tradução de suculentos jogos de palavras, sem perder o sabor. Revista Estudos da Linguagem, v. 23, n. 3, p. 681-693, $2015 \mathrm{~b}$. 
TEIXEIRA, E. D. Linguística de Corpus no Brasil, ontem e hoje: uma entrevista com Stella Esther Ortweiler Tagnin. Belas Infiéis, v. 6, n. 1, p. 163-175, 2017.

TEIXEIRA, E. D.; TAGNIN, S. E. O. Vocabulário para Culinária inglês-português. São Paulo: SBS, 2008. 